\title{
Phylogenetic groups and cephalosporin resistance genes of Escherichia coli from diseased food-producing animals in Japan
}

\author{
Tetsuo Asai ${ }^{1 *}$, Kaori Masani ${ }^{2}$, Chizuru Sato², Mototaka Hiki ${ }^{1}$, Masaru Usui ${ }^{1}$, Kotaro Baba', Manao Ozawa',
} Kazuki Harada ${ }^{2}$, Hiroshi Aoki ${ }^{2}$ and Takuo Sawada ${ }^{2}$

\begin{abstract}
A total of 318 Escherichia coli isolates obtained from different food-producing animals affected with colibacillosis between 2001 and 2006 were subjected to phylogenetic analysis: 72 bovine isolates, 89 poultry isolates and 157 porcine isolates. Overall, the phylogenetic group A was predominant in isolates from cattle $(36 / 72,50 \%)$ and pigs $(101 / 157,64.3 \%)$ whereas groups A $(44 / 89,49.4 \%)$ and D (40/89, 44.9\%) were predominant in isolates from poultry. In addition, group B2 was not found among diseased food-producing animals except for a poultry isolate. Thus, the phylogenetic group distribution of $E$. coli from diseased animals was different by animal species. Among the 318 isolates, cefazolin resistance (minimum inhibitory concentrations: $\geq 32 \mu \mathrm{g} / \mathrm{ml}$ ) was found in six bovine isolates, 29 poultry isolates and three porcine isolates. Of them, 11 isolates (nine from poultry and two from cattle) produced extended spectrum $\beta$-lactamase (ESBL). The two bovine isolates produced bla $a_{C T X-M-2,}$ while the nine poultry isolates produced bla $a_{C T X-M-25}(4), b / a_{S H V-2}$ (3), bla $a_{C T X-M-15}$ (1) and bla $a_{C T X-M-2}$ (1). Thus, our results showed that several types of ESBL were identified and three types of $\beta$-lactamase (SHV-2, CTX-M-25 and CTX-M-15) were observed for the first time in E. coli from diseased animals in Japan.
\end{abstract}

Keywords: Escherichia coli, food-producing animals, cephalosporin resistance, extended spectrum $\beta$ ? $\beta$ ?-lactamase, AmpC $\beta$ ? $\beta$ ?-lactamase, phylogenetic grouping

\section{Findings}

Pathogenic Escherichia coli is the causative agent of colibacillosis that brings severe clinical sighs such as diarrhea, meningitis and sepsis in domestic animals. E. coli can be divided into four phylogenetic groups using multiplex PCR method [1]. Several authors have analyzed the distribution of the main phylogenetic groups among E. coli strains isolated from human and animals. Extraintestinal pathogenic $E$. coli usually belongs to groups $\mathrm{B} 2$ and $\mathrm{D}$, while the commensal strains are groups $\mathrm{A}$ and B1 in humans [2]. In healthy food-producing animals, a predominant distribution of group B1 was reported in E. coli from cattle, while group A was predominantly prevalent in pigs and chickens [3-5]. On the contrary, although predominant phylogenetic groups

\footnotetext{
*Correspondence: asai-t@nval.maff.go.jp

'National Veterinary Assay Laboratory, Ministry of Agriculture, Forestry and

Fisheries, 1-15-1 Tokura, Kokubunji, Tokyo 185-8511

Full list of author information is available at the end of the article
}

were reported in E. coli from diseased poultry [6-8], little information regarding to diseased cattle and pigs was available.

Antimicrobial agents have been widely used for treatment of colibacillosis in domestic animals. Antimicrobial resistance is more frequently found in E. coli isolates from diseased animals than apparently healthy animals [9]. Increases in cephalosporin-resistant E. coli in domestic animals have been a significant worldwide concern including Japan. Extended-spectrum $\beta$-lactamase (ESBL)-producing isolates of $E$. coli were identified in domestic animals around 2000 in Japan [10,11]. The third and greater generation cephalosporin antibiotics are clinically important antimicrobial agents in human and animal medicines. Such agents are approved to treat bacterial diseases in cattle and pigs and not licensed for enhancing animal growth in Japan. However, cephalosporin-resistant $E$. coli has been identified in isolates from not only cattle and pigs but also poultry in Japan 
$[10,12]$. At present the reason for the prevalence of cephalosporin-resistant $E$. coli in poultry is unclear.

In the present study, we determined the distribution of phylogenetic groups in E. coli from food-producing animals affected with colibacillosis in Japan. In addition, we examined the characteristics of cephalosporin-resistant isolates of $E$. coli from the diseased animals.

A total of $318 E$. coli isolates from different animals affected with colibacillosis between 2001 and 2006 throughout Japan were used in this study: 72 bovine isolates, 89 poultry isolates and 157 porcine isolates in 23 , 20 and 28 prefectures, respectively, located from north to south Japan. All the strains were stored in $10 \%$ skimmed milk at $-80^{\circ} \mathrm{C}$ until use. The phylogenetic grouping was performed by multiplex PCR as described by Clermont et al. [1].

The minimum inhibitory concentration (MIC) of cefazolin (CEZ) was determined by an agar dilution method in accordance with the guidelines of the Clinical Laboratory Standards Institute (CLSI) $[13,14]$. The MIC of some of the isolates to CEZ was previously determined [15]. Susceptibilities of CEZ-resistant isolates to several $\beta$-lactamase antibiotics, cefpodoxime, cefotaxime, ceftazidime, aztreonam, imipenem and meropenem were tested according to the CLSI guideline $[13,14]$ using the commercially available broth microdilution test (Eiken Co. LTD, Tokyo, Japan). E. coli ATCC 25922 and Pseudomonas aeruginosa ATCC 27853 were used as quality controls for MIC determination. The Chi-square test was performed on the antimicrobial susceptibility and the phylogenetic subgroup data. The resistance rates in each phylogenetic group were compared with those in the overall strains tested. For each comparison, a $P$ value of $<0.05$ was considered to denote significant differences.

A double-disk synergy test for detection of ESBLs was performed using clavulanate and cefotaxime, ceftazidime, cefpodoxime, or aztreonam disks (Nissui Pharmaceutical Co., Ltd., Tokyo, Japan) as previously described [10]. Detection of $\beta$-lactamase genes was carried out by PCR using primers for $b l a_{T E M}, b l a_{S H V}$ and $b l a_{P S E-1}$ as described previously [10]. Multiplex PCR was applied to the AmpC genes, groups ACC, FOX, MOX, CIT and EBC, detection as previously described [16]. As for samples positive for CIT group, sequence analysis was performed using the primer pairs for amplification of the full-length gene of $b l a_{C M Y-2}$ [10]. Multiplex PCR was used for blaCTX-M detection as previously described [17]. Subtypes of CTX$\mathrm{M} \beta$-lactamases were determined using the primer pairs as follows: CTX-MF (5'-GACTATTCATGTTGTTGTTATTTC-3') and CTX-MR (5'-TTACAAACCGTTGGTGACG-3') for CTX-M-group1 [18]; bla CTX-M-2 $_{2}$ F (5'ATGATGACTCAGAGCATTCG-3') and $b a_{C T X-M-2} \mathrm{R}\left(5^{\prime}-\right.$ TCAGAAACCGTGGGTTACGA-3') for CTX-M-group2
[10]; CTXM825F (5'-CGCTTTGCCATGTGCAGCACC3') [19] and CTXM20 (5'-ATAACCGTCGGTGACAATT3') [17] for CTX-M-group 8 and 25/26. Nucleotide sequences were preformed directly on both strands of PCR products by using dye terminator chemistry. The DNA alignments and deduced amino acid sequences were examined using the BLAST program (National Center for Biotechnology Information, USA).

The phylogenetic analysis revealed that 318 isolates of E. coli from diseased animals were classified into four phylogenetic groups (Table 1). The phylogenetic group A was commonly predominant in isolates from cattle (36/72, 50\%) and pigs $(101 / 157,64.3 \%)$ whereas groups A $(44 / 89,49.4 \%)$ and D $(40 / 89,44.9 \%)$ were predominant in isolates from poultry. The B2 group was rarely found in E. coli from healthy cattle, chickens and pigs in Brazil [3] as well as Japan. In Korea, group B2 was also not found in E. coli isolates from food-producing animals [4]. These trends were similar to those of the present study although clinical isolates from foodproducing animals were used here. On the other hand, in the United States, groups A and D were predominant (38\% and $28 \%$, respectively) in E. coli from diseased poultry and group B2 was also found in 19\% [6]. In European countries, group B2 was often isolated from diseased poultry $[7,8]$. Thus, the distribution of phylogenetic groups may be determined not only by the animal species but also by their health status or geographical region.

Previous studies showed that the phylogenetic group distribution may be related to antimicrobial resistance prevalence in human isolates of E. coli [20]. In the present study, 38 (11.9\%) isolates exhibited CEZ resistance (MIC: $\geq 32 \mu \mathrm{g} / \mathrm{ml}$ ) (Table 2). Twenty-six (68.4\%) of the CEZ-resistant isolates belonged to group A. However, rates of CEZ resistance among the phylogenetic groups, except for group B2, were in $8.6-14.4 \%$. Thus, no significant difference in the resistance rates between the phylogenetic groups was observed.

Of the 38 resistant isolates, 11 isolates from two cattle and nine poultry produced ESBLs while the remaining 27 isolates produced AmpC $\beta$-lactamase. The two bovine isolates expressed $b l a_{C T X-M-2}$, while, of the nine poultry, four expressed $b l a_{C T X-M-25}$, three expressed $b l a_{S H V-2}$, one expressed $b l a_{C T X-M-15}$ and one expressed $b l a_{C T X-M-2}$. The $b l a_{T E M-1}$ gene, being non-ESBL, was detected in 12 isolates. This is the first description of the $b l a_{S H V-2}, b l a_{C T X-M-15}$ and $b l a_{C T X-M-25}$ enzymes in $E$. coli from food-producing animals in Japan. In human patients in Japan, E. coli strains carrying $b l a_{C T X-M-2}$ were predominantly prevalent around 1997 [21], and then the dominant $\beta$-lactamase type has changed to the CTX-M9 group, including $b l a_{C T X-M-14}$ and $b l a_{C T X-M-16}$, since 2001 [22]. As for food-producing animals, E. coli 
Table 1 Distribution of Escherichia coli isolate phylogenetic groups from diseased animals in Japan between 2001 and 2006

\begin{tabular}{lrrrrrrrr}
\hline Phylogenetic group & \multicolumn{3}{c}{ No. of isolates tested } & \multicolumn{3}{c}{ No. of isolates resistant to cefazolin (\%) } \\
\cline { 2 - 9 } & Cattle & Poultry & Swine & Total & Cattle & Poultry & Swine & Total \\
\hline A & 36 & 44 & 101 & 181 & $3(8.3)$ & $21(47.7)$ & $2(2.0)$ & $26(14.4)$ \\
B1 & 18 & 4 & 9 & 31 & $2(11.1)$ & $1(25.0)$ & $0(0)$ & $3(9.7)$ \\
B2 & 0 & 1 & 0 & 1 & $0(\mathrm{NA})$ & $0(0)$ & $0(\mathrm{NA})$ & $0(0)$ \\
D & 18 & 40 & 47 & 105 & $1(5.6)$ & $7(17.5)$ & $1(2.1)$ & $9(8.6)$ \\
\hline Total & 72 & 89 & 157 & 318 & $6(8.3)$ & $29(32.6)$ & $3(1.9)$ & $38(11.9)$ \\
\hline
\end{tabular}

* NA: not applicable

carrying $b l a_{C T X-M-2}$ have emerged in apparently healthy broilers [10] and cattle [11] in 2000 and pigs in 2003 [12]. In 2002, bla $a_{C T X-M-18}$, identical to amino acid sequence of bla $a_{C T X-M-14}$, was identified in cephalosporin-resistant isolates from healthy broilers [10]. On the other hand, of the remaining $27 \mathrm{AmpC} \beta$-lactamase producing isolates, 13 isolates were PCR positive for CIT group, being identified bla $a_{C M Y-2}: 10$ from poultry, two from cattle and one from swine (Table 2). There were no positive signals for group ACC, FOX, MOX and $\mathrm{EBC}$. The $b l a_{C M Y-2}$ gene was found to be prevalent in a wide range of food-producing animal species in Japan $[10,12]$, as well as other countries [23].

In the present study, 5 of 8 isolates producing CTX-M ESBL and all three isolates producing SHV-type ESBL belonged to group A. However, group B2 is predominant in SHV-type ESBL producing E. coli isolates of human origin whereas group D is predominant in CTX$\mathrm{M}$ enzyme-producing isolates [24]. On the contrary, 7 of 13 isolates producing CMY- $2 \beta$-lactamase belonged to group A. Group B1 was dominant in CMY enzyme-producing E. coli from retail broiler meats [25]. It is likely

Table 2 MICs of $\beta$-lactam antibiotics for 38 cefazolin-resistant isolates of $E$. coli from diseased animals isolated between 2002 and 2006

\begin{tabular}{|c|c|c|c|c|c|c|c|c|c|c|c|}
\hline \multirow{3}{*}{$\begin{array}{l}\text { Animal } \\
\text { species }\end{array}$} & \multirow{3}{*}{$\begin{array}{l}\beta \text { - } \\
\text { lactamase }\end{array}$} & \multirow{3}{*}{$\mathrm{n}$} & \multirow{3}{*}{$\begin{array}{c}\text { Year } \\
\text { isolated }\end{array}$} & \multirow{3}{*}{$\begin{array}{l}\text { Phylogenetic } \\
\text { group }\end{array}$} & \multicolumn{7}{|c|}{ MICs $(\mu \mathrm{g} / \mathrm{ml})$ of: } \\
\hline & & & & & Cefazolin & Cefpodoxime & Cefotaxime & Ceftazidime & Aztreonam & Imipenem & Meropenem \\
\hline & & & & & $(32)^{*}$ & (8) & (64) & (32) & (32) & (16) & (16) \\
\hline \multirow[t]{6}{*}{ Cattle } & CTX-M-2 & 1 & $2003(1)$ & $A(1)$ & 256 & $>32$ & $>32$ & 4 & 16 & $\leq 1$ & $\leq 4$ \\
\hline & $\begin{array}{l}\text { CTX-M-2/ } \\
\text { TEM-1 }\end{array}$ & 1 & $2003(1)$ & B1 (1) & 256 & $>32$ & $>32$ & 8 & $>16$ & $\leq 1$ & $\leq 4$ \\
\hline & CMY-2 & 1 & $2003(1)$ & $A(1)$ & 256 & 8 & $\leq 1$ & $\leq 1$ & $\leq 4$ & $\leq 1$ & $\leq 4$ \\
\hline & $\begin{array}{l}\text { CMY-2/ } \\
\text { TEM-1 }\end{array}$ & 1 & $2002(1)$ & $\mathrm{D}(1)$ & 256 & $>32$ & 8 & 16 & $\leq 4$ & $\leq 1$ & $\leq 4$ \\
\hline & TEM-1 & 1 & $2003(1)$ & A (1) & 32 & 8 & $\leq 1$ & 2 & $\leq 4$ & $\leq 1$ & $\leq 4$ \\
\hline & ND & 1 & $2002(1)$ & B1 (1) & 128 & 16 & $\leq 1$ & 8 & $\leq 4$ & $\leq 1$ & $\leq 4$ \\
\hline \multirow[t]{7}{*}{ Poultry } & CTX-M-2 & 1 & 2006 & $A(1)$ & $>512$ & $>32$ & $>32$ & 2 & $\leq 4$ & $\leq 1$ & $\leq 4$ \\
\hline & $\begin{array}{l}\text { CTX-M-15/ } \\
\text { TEM-1 }\end{array}$ & 1 & 2006 & $A(1)$ & $>512$ & $>32$ & $>32$ & 32 & 8 & $\leq 1$ & $\leq 4$ \\
\hline & CTX-M-25 & 4 & $\begin{array}{l}2005(3) \\
2006(1)\end{array}$ & $A(2), D(2)$ & $>512$ & $>32$ & $16->32$ & $2-4$ & $\leq 4-8$ & $\leq 1$ & $\leq 4$ \\
\hline & $\mathrm{SHV}-2$ & 3 & $2004(3)$ & A (3) & $256-512$ & $32->32$ & $8-32$ & $4-16$ & $\leq 4-8$ & $\leq 1$ & $\leq 4$ \\
\hline & CMY-2 & 10 & $\begin{array}{c}2004(1) \\
2006 \\
(10)\end{array}$ & $\mathrm{A}(5), \mathrm{B} 1(1), \mathrm{D}$ & $512->512$ & $>32$ & $4-32$ & $8-32$ & $\leq 4-8$ & $\leq 1$ & $\leq 4$ \\
\hline & TEM-1 & 7 & $\begin{array}{l}2004(2), \\
2005(5)\end{array}$ & $A(7)$ & $64->512$ & $16-32$ & $\leq 1-2$ & $4-8$ & $\leq 4$ & $\leq 1$ & $\leq 4$ \\
\hline & ND & 2 & $\begin{array}{l}2002(1) \\
2005(1)\end{array}$ & A (2) & $128-256$ & $16-32$ & $\leq 1-2$ & 4 & $\leq 4$ & $\leq 1$ & $\leq 4$ \\
\hline \multirow[t]{2}{*}{ Swine } & $\begin{array}{l}\text { CMY-2/ } \\
\text { TEM-1 }\end{array}$ & 1 & $2004(1)$ & A (1) & $>512$ & $>32$ & 16 & 32 & 16 & $\leq 1$ & $\leq 4$ \\
\hline & ND & 2 & $\begin{array}{l}2002(1) \\
2003(1)\end{array}$ & $A(1), D(1)$ & $128-256$ & $4-8$ & $\leq 1$ & $\leq 1$ & $\leq 4$ & $\leq 1$ & $\leq 4$ \\
\hline
\end{tabular}

\footnotetext{
* Resistance breakpoint $(\mu \mathrm{g} / \mathrm{ml})$ defined by CLSI guideline.
} 
that the genotype of $E$. coli carrying $\beta$-lactamase genes may be different between humans and food-producing animals.

It is essential to understand the prevalence of resistance to clinically important antimicrobials in bacteria from food-producing animals. The MICs of six $\beta$-lactam antibiotics are summarized in Table 2. All CEZ-resistant isolates were susceptible to imipenem and meropenem. All isolates exhibit cefpodoxime resistance (MIC of breakpoint: $\geq 8 \mu \mathrm{g} / \mathrm{ml}$ ) except for one porcine isolate in which $\beta$-lactamase expression was not determined. All isolates expressing CTX-M enzymes exhibit cefotaxime resistance (MIC of breakpoint: $\geq 64 \mu \mathrm{g} / \mathrm{ml}$ ) with the exception of one poultry isolate (MIC: $16 \mu \mathrm{g} / \mathrm{ml}$ ) harboring bla $a_{C T X-M-25}$. Resistance to ceftazidime was found in three poultry and one porcine isolate with $b l a_{C M Y-2}$, and one poultry isolate with $b l a_{C T X-M-15}$. Resistance to aztreonam was found in a single bovine isolate with bla $_{C T X-M-2}$. The MICs of antimicrobials tested varied in isolates with each $\beta$-lactamase gene.

In conclusion, our study suggests that the distribution of phylogenetic groups in $E$. coli from diseased domestic animals varies regionally in addition to animal species. Moreover, ESBL-producing E. coli from the animals were frequently assigned to a specific group, being different from human ESBL isolates. Further study on ESBL-producing E. coli from several animal sources using the PCR-based phylogenetic typing and the other genotyping methods may clarify the relationship of the resistant bacteria and/or the resistance determinants prevalent in the food-chain and the environments.

\section{Abbreviations}

CEZ: cefazoline; CLSI: Clinical and Laboratory Standards Institute; ESBL: extended spectrum $\beta$-lactamase; ESC: extended-spectrum cephalosporinase: MICs: Minimum inhibitory concentrations.

\section{Acknowledgements}

We thank the staff of the Livestock Hygiene Service Centers across Japan for providing E. coli isolates. This work was supported in part by a grant-in-aid from the Japanese Ministry of Health, Labour and Welfare (H21-ShokuhinIppan-013).

\section{Author details}

${ }^{1}$ National Veterinary Assay Laboratory, Ministry of Agriculture, Forestry and Fisheries, 1-15-1 Tokura, Kokubunji, Tokyo 185-8511. ${ }^{2}$ Nippon Veterinary and Life Science University, 1-7-1 Kyonancho, Musashino, Tokyo 180-8601, Japan.

\section{Authors' contributions}

TA conceived the study, the study design, interpreted the data and drafted the manuscript. KM carried out large parts of the resistance gene determination. CS helped to carried out resistance gene determination. $\mathrm{MH}$ helped to carry out determination of phylogenetic groups. MU helped to carried out resistance gene determination. KB carried out antimicrobial susceptibility testing. MO carried out antimicrobial susceptibility testing. $\mathrm{KH}$ carried out antimicrobial susceptibility testing and helped to draft the manuscript. HA helped to carry out the resistance gene determination and draft the manuscript. TS helped to draft the manuscript. All authors read and approved the final manuscript.

\section{Competing interests}

The authors declare that they have no competing interests.

Received: 21 July 2011 Accepted: 12 October 2011

Published: 12 October 2011

\section{References}

1. Clermont $\mathrm{O}$, Bonacorsi S, Bingen E: Rapid and simple determination of the Escherichia coli phylogenetic group. Appl Environ Microbiol 2000, 66:4555-4558.

2. Johnson JR, Delavari P, Kuskowski M, Stell AL: Phylogenetic distribution of extraintestinal virulence-associated traits in Escherichia coli. J Infect Dis 2001, 183:78-88.

3. Carlos C, Pires MM, Stoppe NC, Hachich EM, Sato MI, Gomes TA, Amaral LA, Ottoboni LM: Escherichia coli phylogenetic group determination and its application in the identification of the major animal source of fecal contamination. BMC Microbiol 2010, 10:161.

4. Unno T, Han D, Jang J, Lee SN, Ko G, Choi HY, Kim JH, Sadowsky MJ, Hur HG: Absence of Escherichia coli phylogenetic group B2 strains in humans and domesticated animals from Jeonnam Province, Republic of Korea. Appl Environ Microbiol 2009, 75:5659-5666.

5. Escobar-Paramo P, Le Menac'h A, Le Gall T, Amorin C, Gouriou S, Picard B, Skurnik D, Denamur E: Identification of forces shaping the commensal Escherichia coli genetic structure by comparing animal and human isolates. Environ Microbiol 2006, 8:1975-1984.

6. Rodriguez-Siek KE, Giddings CW, Doetkott C, Johnson TJ, Fakhr MK, Nolan LK: Comparison of Escherichia coli isolates implicated in human urinary tract infection and avian colibacillosis. Microbiology 2005, 151:2097-2110.

7. Ewers C, Antao EM, Diehl I, Philipp HC, Wieler LH: Intestine and environment of the chicken as reservoirs for extraintestinal pathogenic Escherichia coli strains with zoonotic potential. Appl Environ Microbiol 2009, 75:184-192.

8. Mora A, Lopez C, Dabhi G, Blanco M, Blanco JE, Alonso MP, Herrera A, Mamani R, Bonacorsi S, Moulin-Schouleur M, et al: Extraintestinal pathogenic Escherichia coli 01:K1:H7/NM from human and avian origin: detection of clonal groups B2 ST95 and D ST59 with different host distribution. BMC Microbiol 2009, 9:132.

9. Harada $\mathrm{K}$, Asai $\mathrm{T}$ : Role of antimicrobial selective pressure and secondary factors on antimicrobial resistance prevalence in Escherichia coli from food-producing animals in Japan. J Biomed Biotechnol 2010, 2010:180682.

10. Kojima A, Ishii Y, Ishihara K, Esaki H, Asai T, Oda C, Tamura Y, Takahashi T, Yamaguchi K: Extended-spectrum-beta-lactamase-producing Escherichia coli strains isolated from farm animals from 1999 to 2002: report from the Japanese Veterinary Antimicrobial Resistance Monitoring Program. Antimicrob Agents Chemother 2005, 49:3533-3537.

11. Shiraki Y, Shibata N, Doi Y, Arakawa Y: Escherichia coli producing CTX-M-2 beta-lactamase in cattle, Japan. Emerg Infect Dis 2004, 10:69-75.

12. Kojima A, Asai T, Ishihara K, Morioka A, Akimoto K, Sugimoto $Y$, Sato T, Tamura $Y$, Takahashi T: National monitoring for antimicrobial resistance among indicator bacteria isolated from food-producing animals in Japan. J Vet Med Sci 2009, 71:1301-1308.

13. CLSI: Performance standards for antimicrobial disk and dilution susceptibility tests for bacteria isolated from animals, 3rd edition. Approved standard M31-A3. Wayne, PA: Clinical and Laboratory Standards Institute; 2008

14. CLSI: Performance standards for antimicrobial susceptibility testing; eighteenth informational supplement. Wayne, PA.: Clinical and Laboratory Standards Institute; 2008

15. Harada K, Asai T, Kojima A, Oda C, Ishihara K, Takahashi T: Antimicrobial susceptibility of pathogenic Escherichia coli isolated from sick cattle and pigs in Japan. J Vet Med Sci 2005, 67:999-1003.

16. Dallenne C, Da Costa A, Decre D, Favier C, Arlet G: Development of a set of multiplex PCR assays for the detection of genes encoding important beta-lactamases in Enterobacteriaceae. J Antimicrob Chemother 2010, 65:490-495.

17. Xu L, Ensor V, Gossain S, Nye K, Hawkey P: Rapid and simple detection of blaCTX-M genes by multiplex PCR assay. J Med Microbiol 2005, 54:1183-1187.

18. Mena A, Plasencia V, Garcia L, Hidalgo O, Ayestaran Jl, Alberti S, Borrell N, Perez $J \mathrm{~L}$, Oliver A: Characterization of a large outbreak by CTX-M-1- 
producing Klebsiella pneumoniae and mechanisms leading to in vivo carbapenem resistance development. J Clin Microbiol 2006, 44:2831-2837.

19. Pitout JD, Hossain A, Hanson ND: Phenotypic and molecular detection of CTX-M-beta-lactamases produced by Escherichia coli and Klebsiella spp. J Clin Microbiol 2004, 42:5715-5721.

20. Moreno E, Prats G, Sabate M, Perez T, Johnson JR, Andreu A: Quinolone, fluoroquinolone and trimethoprim/sulfamethoxazole resistance in relation to virulence determinants and phylogenetic background among uropathogenic Escherichia coli. J Antimicrob Chemother 2006, 57:204-211.

21. Yagi T, Kurokawa H, Shibata N, Shibayama K, Arakawa Y: A preliminary survey of extended-spectrum beta-lactamases (ESBLs) in clinical isolates of Klebsiella pneumoniae and Escherichia coli in Japan. FEMS Microbiol Lett 2000, 184:53-56.

22. Shibata N, Kurokawa H, Doi Y, Yagi T, Yamane $K$, Wachino J, Suzuki S, Kimura K, Ishikawa S, Kato H, et al: PCR classification of CTX-M-type betalactamase genes identified in clinically isolated gram-negative bacilli in Japan. Antimicrob Agents Chemother 2006, 50:791-795.

23. Li XZ, Mehrotra M, Ghimire S, Adewoye L: beta-Lactam resistance and beta-lactamases in bacteria of animal origin. Vet Microbiol 2007, 121:197-214.

24. Branger C, Zamfir O, Geoffroy S, Laurans G, Arlet G, Thien HV, Gouriou S, Picard B, Denamur E: Genetic background of Escherichia coli and extended-spectrum beta-lactamase type. Emerg Infect Dis 2005, 11:54-61.

25. Dhanji H, Murphy NM, Doumith M, Durmus S, Lee SS, Hope R, Woodford N, Livermore DM: Cephalosporin resistance mechanisms in Escherichia coli isolated from raw chicken imported into the UK. J Antimicrob Chemother 2010, 65:2534-2537.

doi:10.1186/1751-0147-53-52

Cite this article as: Asai et al:: Phylogenetic groups and cephalosporin resistance genes of Escherichia coli from diseased food-producing animals in Japan. Acta Veterinaria Scandinavica 2011 53:52.

\section{Submit your next manuscript to BioMed Central} and take full advantage of:

- Convenient online submission

- Thorough peer review

- No space constraints or color figure charges

- Immediate publication on acceptance

- Inclusion in PubMed, CAS, Scopus and Google Scholar

- Research which is freely available for redistribution

Submit your manuscript at www.biomedcentral.com/submit
Biomed Central 